\title{
Friderik Baraga, A Theoretical and Practical Grammar of the Otchipwe Language
}

\author{
$(\text { Detroit, 1850 })^{1}$
}

\begin{abstract}
Alenka Gložančev
IZVLEČEK: V poročilu o angleško pisani slovnici Friderika Barage A Theoretical and Practical Grammar of the Otchipwe Language (Detroit, 1850) je predstavljeno eno najvidnejših del t. $i$. misijonske lingvistike. Kljub temu da ga je kot pionirsko delo s tega jezikoslovnega področja opravil prav slovenski misijonar, doslej v slovenskem prostoru še ni bilo predstavljeno. Z osnovno strukturo slovnice so v sestavku prikazane značilnosti očipvejščine kot manj znanega neindoevropskega jezika ter Baragov konceptualni pristop. Slovnica je bila namreč po njegovem mnenju nujna predhodna stopnja za že snujoči slovar očipvejskega jezika, ki mu je nekaj let kasneje dal naslov $A$ Dictionary of the Otchipwe Language (prim. predstavitev tega slovarja $v$ Jezikoslovnih zapiskih 6).
\end{abstract}

ABSTRACT: The article on Friderik Baraga's $A$ Theoretical and Practical Grammar of the Otchipwe Language (Detroit, 1850; written in English) presents one of the most outstanding works in the field of the so called missionary linguistics. It was a Slovenian missionary of all people who carried out a pioneer work in this linguistic field; but in spite of that this work has not yet been presented in his native country. Through the basic grammatical structure the article presents the characteristic features of the Otchipwe language as a relatively poorly known non-Indo-European language, as well as Baraga's conceptual

1 Prispevek je bil z delovnim naslovom Slovnica slovenskega misijonarja Friderika Barage A Theoretical and Practical Grammar of the Otchipwe Language: slovnica - tudi kot teoretično izhodišče za slovar pripravljen za strokovni sestanek (zlasti) Leksikološke sekcije Inštituta za slovenski jezik Frana Ramovša ZRC SAZU (organizator in sklicatelj: dr. Andreja Žele, vodja Leksikološke sekcije) in na sestanku 6. 11. 2001 tudi predstavljen. - Na tem mestu naj ob omembi strokovnega sestanka omenim tudi živahno strokovno razpravo na koncu, ki se je nanašala zlasti na tri posebej zanimive probleme iz Baragove slovnice $A$ Theoretical and Practical Grammar of the Otchipwe Language: (1) očipvejščina kot neindoevropski jezik (kam globinsko genetsko spada) - pojasnilo je podal dr. Vladimir Nartnik; (2) kategorija »živosti« pri samostalnikih in glagolih; aktivni jeziki (nasproti ergativnim jezikom) - pojasnilo je podal dr. Vladimir Nartnik; (3) kategorija dubitativa (kako se prevaja v npr. angleščino, slovenščino; kaj je specifično za očipvejskei dubitativ) - v razpravi več sodelujočih. 
approach. Namely, he considered the grammar to be the necessary foundation for the dictionary of the Otchipwe language that he had already conceived. Only a few years later he published it under the title A Dictionary of the Otchipwe Language (cf. the presentation of this dictionary in Jezikoslovni zapiski 6).

\section{Utemeljitev za predstavitev Baragove slovnice}

Za izbrano temo - naslov ob predstavitvi (prim. opombo 1) je bil Slovnica slovenskega misijonarja Friderika Barage A Theoretical and Practical Grammar of the Otchipwe Language: slovnica tudi kot teoretično izhodišče za slovar - sta zlasti dva razloga: 1.1 jezikoslovni in 1.2 avtorsko predstavitveni.

1.1 Naslov izbrane teme nakazuje posebno jezikoslovno področje t. i. misijonske lingvistike, podnaslov pa za jezikoslovje temeljno, bistveno povezavo dveh jezikoslovnih področij: slovnice in slovarja. Nujnosti te medsebojne povezave se na splošno morda premalo zavedamo; za potrditev te predpostavke naj bo npr. prevod citata, da so »leksikografske napake pogosto posledica nerešenih leksikoloških in slovničnih problemov« (B. Tafra, Jezikoslovna razdvojba, Zagreb 1995, str. 64). Pomen slovnice za slovaropisje je predstavljen na zelo »oddaljenem, posebnem " primeru: gre za jezikoslovno delo Friderika Barage oz. natančneje za Baragovo slovnico; v njej se že iz avtorjevih opomb eksplicitno vidi, da jo je pisal tudi $\mathrm{z}$ mislijo na bodoči, v istem času že snujoči slovar, saj v Uvodu pravi, da »s slovnico med drugim dela tudi temelj za načrtovani slovar očipvejskega jezika«. Ta »oddaljen, poseben « primer je torej očipvejščina, eden od indijanskih jezikov, ki ga govori pleme Očipvejcev. Konkretno: leta 1850 je v Detroitu izšla izšla slovnica A Theoretical and Practical Grammar of the Otchipwe Language Friderika Barage, leta 1853 pa v Montrealu še njegov slovar A Dictionary of Otchipwe Language (Explained in English), ki mu je nato sledil še obrnjeni angleško-očipvejski slovar kot njegov drugi del. Slovnica ima okrog 550 strani, slovar pa okrog 420 strani; torej gre tudi za obsegovno temeljiti deli.

1.2 Tema je bila posredno izbrana tudi zato, da se osvetli Baraga kot sicer manj znan, lahko bi rekli ljubiteljski slovenski jezikoslovec, ki pa je s svojim jezikoslovnim delom izkazal visoko profesionalnost. Friderik Baraga v jezikoslovju sprva preseneča, saj je znan zlasti kot misijonar iz srede 19 . stoletja. ${ }^{2}$ Bil je Prešernov in Čopov in ne nazadnje (če gledamo jezikoslovce) tudi Kopitarjev sodobnik. Lahko torej rečemo, da je »predstavnik slovenske romantike«. Gre za izjemno osebnost: Friderik Baraga je namreč poleg svojega osnovnega poslanstva - 40-letnega misijonarskega dela v podnebno težavnih razmerah Severne Amerike oz. Kanade med Indijanci opravil še obsežno jezikoslovno delo, in to, čeprav nejezikoslovec, na visoko profesionalni ravni, kar mu z vsemi superlativi in s poudarkom, da je Bara-

2 Za nekaj osnovnih podatkov iz njegovega življenja in delovanja prim. članek iste avtorice $z$ naslovom Slovenski misijonar Friderik Baraga - tudi kot jezikoslovec, Jezikoslovni zapiski 6, 2000, str. 175-181. 
govo jezikoslovno delo še danes ena od pomembnih referenc za sodobne lingviste, priznava tudi prof. John Nichols v predgovoru k slovarju A Dictionary of Ojibway Language, ki je kot ponatis izšel leta 1992 v ameriškem mestu St. Paulu.

\section{Osnovna struktura in nekaj splošnih značilnosti Baragove} slovnice $A$ Theoretical and Practical Grammar of the Otchipwe Language

\section{Standardni začetni spremni deli:}

Avtorjev (torej Baragov) Predgovor (Preface)

Avtorjev (torej Baragov) Uvod (Introduction)

\section{Slovnica (v pravem pomenu besede) s tremi glavnimi deli (three parts ${ }^{3}$ )}

Prvi del: Ortografija (Part I: Orthography)

Drugi del: Etimologija (Part II: Etymology)

Tretji del: Skladnja (Part III: Syntax)

Zaključni konkretno učbeniški del: Nekaj pogovornih fraz in dva konkretna Pogovora med misijonarjem in Očipvejcem (seveda $v$ očipvejščini in $z$ dodanim angleškim prevodom). S tem Baraga v slovnici pokaže na živo besedilno rabo očipvejščine.

Slovnica je pisana klasično, jasno, pregledno; je deskriptivna slovnica očipvejskega jezika, sicer pisana v angleščini. Baraga ob teoretičnih opisih posameznih jezikovnih kategorij že sproti podaja mnogo primerov, kar da slovnici tudi značaj učbenika očipvejskega jezika.

\section{Pregledni prikaz Baragove slovnice $A$ Theoretical and Practical Grammar of the Otchipwe Language z nekaj zanimivostmi iz vsakega poglavja}

Standardni začetni spremni deli

Predgovor:

1 Baraga poudari težavnost sestavljanja slovnice očipvejščine, saj je pisana le na podlagi govorjenega jezika.

2 Baragova opredelitev namena slovnice

2.1 Slovnica bo namenjena zlasti misijonarjem kot nujno potreben komunikacijski priročnik.

3 Ker je slovnica pisana $v$ angleščini, so tudi pri tem pregledu podani angleški naslovi ali siceršnji citirani ali povzeti deli besedila, kot avtorica prispevka za strokovni inštitutski sestanek (in po njem tudi za prispevek za Jezikoslovne zapiske) pa sem dodala slovenske prevode. - Naslovi glavnih delov sprva presenečajo, vendar bo v nadaljevanju ta tipologija nekoliko razjasnjena. 
Alenka Gložančev, Friderik Baraga, A theoretical and Practical Grammar of the ...

2.2 Slovnica bo uporabna tudi za jezikoslovce, zlasti pri raznih primerjalnih študijah, predvsem med t. i. primitivnimi jeziki in civiliziranimi jeziki.

Uvod:

1 Umestitev očipvejščine

1.1 Govorci: Očipvejci (torej pleme Očipva, ki je eno od plemen Indijancev); v Baragovem času je bilo Očipvejcev okrog 15.000 .

1.2 Kraj: Kanada, torej Severna Amerika, področje ob Velikih jezerih oz. ob Reki sv. Lovrenca.

1.2.1 Glavna plemena Indijancev na tem področju: Očipva, Otava, Potavami.

1.3 Širša jezikovna skupina: očipvejščina ni indoevropski jezik; je eden od jezikov t. i. algonkijanske jezikovne skupine; očipvejščina ima v tej skupini še največ govorcev; jeziki bližnjih plemen, npr. plemena Otava, so kot nekakšni dialekti.

\section{Slovnica ( $v$ pravem pomenu besede) $s$ tremi sestavnimi deli (three parts)}

\section{Prvi del: Ortografija (Part I: Orthography)}

Baraga $v$ začetni definiciji pojasni, da ne gre za pravopis, ampak ortografijo v klasičnem, grškem pomenu besede: torej v smislu črkopisa in s tem povezanega glasoslovja.

$\infty$

$\cdot$

\section{1 Črkopis}

Ker je bila očipvejščina do tedaj le govorjeni jezik, je moral Baraga za pisno predstavitev najprej poiskati oz. oblikovati ustrezen črkopis.

Dve temeljni načeli za Baragovo oblikovanje črkopisa za očipvejščino:

1.1 Za osnovo je vzel tamkajšnjemu področju bližnji angleški in francoski črkopis in ju seveda prilagodil očipvejskim glasovom.

1.2 Pregled črkopisa da misliti, da je bil Baraga očitno tudi pod vplivom slovenščine ali vsaj tendence v njej (saj vemo, da gre za čas »abecedne vojne «v takratnem slovenskem »Prešernovem « času). Odločil se je namreč za enostavno načelo: en glas - ena črka, če se le da. (Črkopis bo predstavljen skupaj s pravili izreke, torej skupaj s pravorečjem, v naslednjem razdelku.)

\section{Glasoslovje}

Baraga je na podlagi predhodne prepoznave očipvejskih glasov, le-te razdelil v dve osnovni, klasični skupini: samoglasnike in soglasnike.

2.1 Vrste glasov in načela izreke:

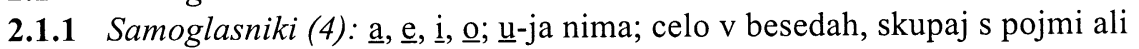
predmeti prevzetih iz angleščine ali francoščine, se v očipvejščini u spremeni v $\underline{\underline{u}}$, npr. mon bouton $\rightarrow$ nin botô $(=\operatorname{moj}$ gumb); un mouchoir $\rightarrow$ moshwe (= robec). Nekaj načel za izreko samoglasnikov:

Osnovno pravilo: Samoglasniki se nikoli ne spremenijo, so torej invariantni. Njihov izgovor je približno tak kot v slovenščini. (Baraga ga seveda pojasni v primerjavi z angleščino, ker gre za angleško pisano slovnico.) 
cu besede), vsi se izgovarjajo enakovredno - tudi če gre za zaporedje dveh ali treh, morajo biti enako slišni (torej se vsi izgovarjajo kot zlogi):

$\underline{\text { Náwaii }}(=\underline{\text { in the middle }}=$ v sredini): $\underline{\text { na-va-i }-i]}$

$\underline{\text { Oosi }}(=\underline{\text { he has }} \underline{\text { a father }}=$ ima očeta): $[\underline{0-0-s i}]$

Samoglasniki imajo v očipvejščini včasih nazalni izgovor, čeprav niso pravi nazali kot npr. v francoščini.

Očipvejščina pozna »specifične diftonge» (tj.: oba samoglasnika se izgovarjata $\mathrm{v}$ enem zlogu, toda oba morata biti enako slišna ( $v$ tem je specifičnost): ta specifični diftong pa povzroči samo kombinacija $i$-ja s kakim od drugih treh samoglasnikov

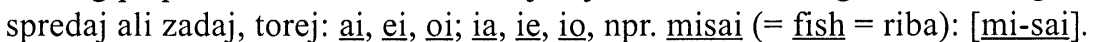

Ker očipvejščina u-ja ne pozna, se celo v besedah, skupaj s pojmi ali predmeti prevzetih iz angleščine ali francoščine, $\underline{u}$ spremeni v $\underline{\mathrm{o}}$, npr. mon bouton $(=\underline{\text { nin }} \underline{\text { botô }}$ $=$ moj gumb); $\underline{\text { un mouchoir }}$ (= $\underline{\text { moshwe }}=$ robec $)$.

V okviru načel za izreko, so obravnavani še naglasi oz. naglasna znamenja: Baraga je naglasna znamenja uporabil v dveh funkcijah:

$\mathrm{V}$ glavnem so naglasna znamenja rabljena za glasoslovje in dostikrat s tem povezano semantiko. Za to jezikovno ravnino uporabi ostrivec in strešico.

Ostrivec pomeni, da mora biti tisti samoglasnik nekoliko močneje izgovorjen; naglasno znamenje ima namreč včasih tudi močno pomensko razlikovalno vlogo, npr.: $\underline{\text { ságaigan }}(=\underline{\text { a small lake }}=$ majhno jezero $)$ : $\underline{\text { sagáigan }}(=\underline{\text { a nail }}=$ žebelj$) ; \underline{\text { níbing }}$ $(=\underline{\text { in the }}$ watter $=v$ vodi $): \underline{\text { nibíng }}(=\underline{\text { in }} \underline{\text { summer }}=$ poleti $)$.

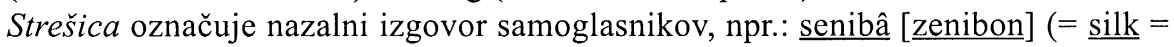
svila), abinodjî [abinodžen] (= a child = otrok).

Poleg ostrivca in strešice je Baraga uporabil tudi krativec, vendar ne za glasoslovje, ampak za oblikoslovje: krativec je sredstvo za ločevanje dveh vrst prve osebe množine, pri čemer gre za kategorijo inkluzivnosti (vključenosti): npr.: endaiàng (= we $\underline{\text { live }}=$ mi živimo): oblika s krativcem pomeni: oseba, ki ji govorimo, ni vključena;

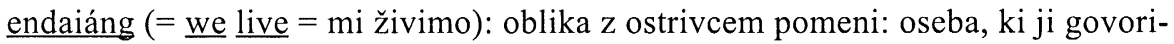
mo, je vključena.

2.1.2 Soglasniki (13): $\underline{\mathrm{b}}, \underline{\mathrm{c}}, \underline{\mathrm{d}}, \mathrm{g}, \underline{\mathrm{h}}, \mathrm{j}, \underline{\mathrm{k}}, \underline{\mathrm{m}}, \underline{\mathrm{n}}, \underline{\mathrm{p}}, \underline{\mathrm{s}}, \underline{\mathrm{t}}, \underline{\mathrm{w}}$.

Nikoli: f, l, q, r, v, x, z.

Nekaj načel za izreko soglasnikov:

Očipvejščina ne razlikuje dobro med $b$ in $p$; med $d$ in $t$; med $g$ in $k$ (zato Očipvejci tudi niso mogli jasno izgovarjati imena Barage). Baraga s predvidevanjem za slovar priporoča, da uporabnik slovarja v slovarju pogleda pod obe »dvomni« črki, če pod eno pričakovane besede ne najde.

Glasova $\underline{f}$ in $\underline{v} v$ prevzetih besedah se izgovarjata kot $\underline{b}$ ali $\underline{p}, n p r$. .: iz francoščine farine $(=v$ očipvejščini panin $(=$ moka $)$ ); ime David $=$ Dabid.

Črka c se nikoli ne uporablja samostojno, ampak samo v kombinaciji tch [čc].

Črka $\underline{h}$ se izgovarja samo v medmetih, in sicer $\mathrm{z}$ močno aspiracijo, npr.: $\underline{\text { haw! [haw] }}$ $(=\underline{\text { hallo }}=$ živjo $)$.

Glavna raba črke $\underline{\mathrm{h}}$ je v povezavi s $\underline{\mathrm{s}}$-jem, torej dvočrkje $\underline{\mathrm{sh}}[\underline{\mathrm{s}}]$.

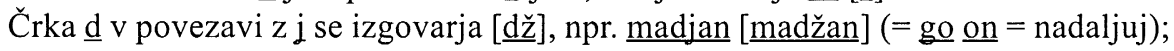
ninindj $[\underline{\text { ninindž }}](=\underline{\text { my hand }}=$ moja roka $)$. 


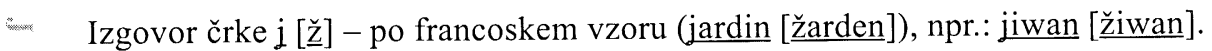

* Črka g se izgovarja [g], npr.: gigito [gigito].= (he speaks $=$ on govori.)

* Črka $\underline{\mathrm{s}}[\underline{\mathrm{z}}]$, vedno: na začetku, sredi ali koncu besede, npr.. nin segis $[\underline{\text { nin }} \underline{\text { zegiz] }}$ (= $\underline{\mathrm{I}}$

fear $=$ bojim se).

Dvočrkje $\underline{\text { ss }}$ se izgovarja kot $[\underline{\mathrm{s}}]$, npr.: ondass $[\underline{\text { ondas }}]$ (= $\underline{\text { come here }}=$ pridi sem). Ipd.

\section{Drugi del: Etimologija (Part II: Etymology)}

Baraga v začetni definiciji pove, da je ta razdelek poimenovan etimologija v skladu s klasičnim, grškim pojmovanjem ${ }^{4}$ : gre za vedo o izvoru besed in v tem smislu bo tu obravnavano: izpeljava (the derivation), pregibanje (inflections) in deli govora (Parts of Speech). - Glede na današnjo terminologijo gre torej za oblikoslovje (z besednimi vrstami) in besedotvorje.

\section{Očipvejščina pozna devet besednih vrst (9 Parts of Speech):}

1. Samostalnik: $\underline{\text { inini }}(=\underline{\operatorname{man}}=$ moški, mož $), \underline{\text { ikwe }}(=\underline{\text { woman }}=$ ženska, žena $)$

2. zaimek: $\underline{\operatorname{nin}}(\underline{I}=\mathrm{jaz}), \underline{\mathrm{kin}}(\mathrm{you}=\mathrm{ti})$, win $(=\underline{\text { he}}, \underline{\text { she }}, \underline{\mathrm{it}}=\mathrm{on}$, ona, ono $)$

3. glagol: $\underline{\text { nin }}$ gigit $(=\underline{I}$ speak $=$ govorim $)$

4. $\quad$ pridevnik: gwanatch $(=\underline{\text { beautiful }=\text { lep}) ~}$

5. števnik: $\underline{\text { midaswi }}(=\underline{\text { ten }}=$ deset $)$; nijtana $(=\underline{\text { twenty }}=$ dvajset $)$

6. predlog: $\underline{\text { nawaii }}(=\underline{\text { in the }} \underline{\text { middle }}=$ sredi); $\underline{\text { megwe }}(=\underline{\text { among }}=$ med $)$

7. prislov: sesika $(=\underline{\text { suddenly }}=$ nenadoma $)$

8. $\quad$ veznik: gaie $(=\underline{\text { and }}=$ in $)$ ishpin $(=\underline{\text { if }}=$ če $)$

9. medmet: $\underline{\text { hoil! }}(=\underline{\text { hallo! }}=$ živjo $)$

\section{Nekaj posebnih pripomb (Baraga: Remarks)}

Pregibne besedne vrste so samostalnik, zaimek in glagol. Pridevnik je nepregibna besedna vrsta; le če se spremeni v glagol, pridobi pregibnost. In v čem se kaže pregibnost? Pri samostalniku in zaimku v tem, da tvorita množino, glagol pa ima zelo razvejano konjugacijo.

Baraga poudarja, da je očipvejščina jezik glagola, ker je »vse odvisno od glagola, vse vanj pretvorljivo in ima tudi zelo razvejano, izredno težko obvladljivo konjugacijo.

Očipvejščina nima člena, ne določnega ne nedoločnega: besedici aw ali $\underline{i w}$, ki so včasih pred samostalniki, niso členi, ampak kazalni zaimki; npr.: $\underline{\text { aw }} \underline{\text { ikwe }}$ (= $\underline{\text { this }}$ $\underline{\text { woman }}=$ ta žena; in ne: the woman).

Vsako besedno vrsto Baraga v slovnici obravnava v samostojnem poglavju (nine chapters = devet poglavij). Ker je problematika zelo obširna in zlasti v nekaterih delih zelo zapletena (kar poudarja tudi Baraga), bom pri vsaki besedni vrsti prikazala le nekaj značilnosti.

4 Podobne tipološko razdelitev poznajo tudi druge slovnice tistega časa, npr. Kopitarjeva, pa tudi že Bohoričeva. 


\section{Poglavje I: Samostalniki}

Kategorija spola: Načeloma očipvejščina (tako kot angleščina, v primerjavi s slovenščino pa prav nasprotno) ne loči spola, kar se vidi pri kombinaciji samostalnika

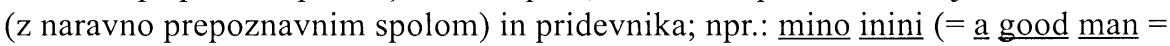
dober moški, dober človek); $\underline{\text { mino }} \underline{\mathrm{ikwe}}(=\underline{\mathrm{a}}$ good woman $=$ dobra žena). (Spola ne

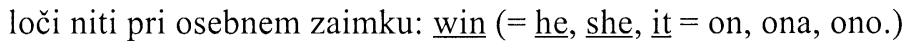

Možnosti za izražanje spola kot naravno pomembne kategorije seveda pozna tudi očipvejščina, in sicer naslednje:

a) t. i. nadomestne osnove za sorodstvena poimenovanja:

$\underline{\text { kwiwisens }}(=\underline{\mathrm{a}} \underline{\mathrm{boy}}=\mathrm{fant})-\underline{\mathrm{ikwésens}}(=\underline{\mathrm{a}} \mathrm{girl}=\operatorname{dekle}) ; \underline{\text { noss }}(=\underline{\text { my }} \underline{\mathrm{father}}=\operatorname{moj}$ oče $)-\underline{\text { mingá }}(=\underline{\text { my }} \underline{\text { mother }}=$ moja mati $)$ ningwíss $(=\underline{\text { my }} \underline{\text { son }}=\operatorname{moj} \sin )-\underline{\text { nindániss }}$ (= $\underline{\text { my daughter }}=$ moja hči);

b) izražanje spola s predponami: nábe + samost. = moški spol, $\underline{\mathrm{ikwé}}+$ samost. $=$ ženski spol; npr.: nábe-pijiki (= bik), ikwé-pijiki (= krava).

V očipvejščini je za samostalnik zelo pomembna kategorija živosti:

a) živi samostalniki (= animate nouns) so tisti, ki označujejo bitja in stvari, ki živijo, so živele, in to resnično ali le domnevno (glede na duhovno sfero Indijancev);

b) neživi samostalniki (= inanimate nouns) označujejo stvari, ki niso nikoli niti domnevno živele.

To razlikovanje je zelo težko, za očipvejščino učečega se povsem nepredvidljivo, zato ga bo, kot napove Baraga, v slovarju označeval: $\underline{a n}$. bo pomenilo animate (živi samost.), in. bo pomenilo inanimete (neživi samost.).

Kategorija samostalniške živosti je v očipvejščini tako pomembna, ker se tesno povezuje z živostjo pri glagolu. T. i. živim samostalnikom namreč pripada povsem svoja konjugacija, torej povsem svoj spregatveni vzorec. Baraga opozarja: če se pomešata živa glagolska konjugacija z neživimi samostalniki, pride ne samo do »kakšne stilne nerodnosti«, ampak do popolne nerazumljivosti oz. nesmiselnosti povedanega.

\section{Poglavje II: Zaimki}

Očipvejščina ima pet razredov zaimkov. - Za ilustracijo bosta predstavljena le dva razreda: osebni zaimki in svojilni zaimki in tudi v okviru teh le nekaj zanimivosti. Osebni zaimki

$\mathrm{V}$ okviru osebnih zaimkov je vsaj v primerjavi s slovenščino in večino sodobnih civiliziranih jezikov zanimivo dejstvo naslednje:

Za 1. os. mn. ima očipvejščina kar štiri osebne zaimke; raba le-teh je določena glede na vrsto sledečega glagola oz. semantično komponento inkluzivnosti naslovnika: nin ali ki; ter ninawind ali kinawind; prvi par se rabi, kadar sledi polnopomenski glagol, od tega nin, če oseba, ki ji govorimo, ni vključena, in ki

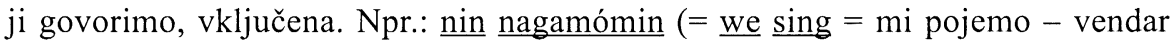
ogovorjeni ni vključen), i nagamómin (= we sing = mi pojemo - ogovorjena oseba je vključena). - Drugi par se rabi ob nepolnopomenskih glagolih: Awenenag igiw negamodjig? - Ninawind sa. (= Who are those that sing? - We do. $=$ Kdo poje? Mi.) 


\section{- Svojilni zaimki:}

-7. V očipvejščini so svojilni zaimki zelo zapletena slovnična kategorija iz več razlogov:

4 Prvi razlog je izjemno veliko število oblik.

Drugi razlog je »vplivna moč svojilnih zaimkov« na t. i. žive samostalnike: Če svojilni zaimek stoji pred živim samostalnikom, dobijo samostalniki različne »svojilne končnice«, različne glede na to, ali se kọnčuje na samoglasnik ali na soglasnik, kako tvori množino ipd., npr.:

Če se samostalnik konča na samoglasnik, dobi svojilno končnico - m, npr.: Kijé$\underline{\text { Manito }}(=\underline{\text { God }}=$ Bog$) ; \underline{\text { nin Kijé-Manitom }}(=\underline{\text { my }} \underline{\text { God }}=\operatorname{moj}$ Bog $) ; \underline{\text { ikwe }}(=\underline{\text { woman }}$ $=$ žena); nind $\underline{\text { ikwem }}(=\underline{\text { my wife }}=$ moja žena $)$.

Če tvori samostalnik množino $\mathrm{z}-a g$, -iag, potem v primeru, da pred njim stoji svojilni zaimek, že v ednini dobi svojilno končnico $\underline{-i m}, n$ nr.: gigo $(=\underline{\text { a }} \underline{\text { ish }}=$ riba $)(\mathrm{mn}$. gigoiag) $>$ nin gigoim $(=\underline{\text { my fish }}=$ moja riba).

Kategorija »svojilnih samostalniških končnic« $v$ odvisnosti od svojilnih zaimkov vsaj v najbolj znanih sodobnih jezikih ne obstaja.

Tretji razlog: Svojilni zaimki pred neživimi samostalniki lahko sprožijo dodajanje posebnih "glagolskih končnic« samostalnikom, sčimer se prvotna zveza samostalnika in svojilnega zaimka spremeni v glagolsko »poved «, npr. nin tchimaniban (= čoln, ki sem ga imel).

Te jezikovne slovnične pretvorbe so zelo zapletene, kažejo pa »vplivno moč svojilnih zaimkov«, ki je ne angleščina (ki je v konkretni Baragovi slovnici razlagalni jezik) ne slovenščina (ki je bila Baragu materinščina) ne poznata (če se omejimo samo na primerjavo v slovnici nekako »prepletajočih se jezikov«.

\section{Poglavje III: Glagol}

Da je očipvejščina »jezik glagola«, kaže tudi obseg Baragove obravnave glagola v njegovi slovnici: od str. $84-422$. Ta besedna vrsta je v očipvejščini zelo zapletena, pri tej predstavitvi bo navedenih le nekaj osnovnih potez:

Očipvejščina nima nedoločnika.

Očipvejščina ne pozna pomožnih glagolov in s tem tudi ne sestavljenih časov ali naklonov. Namesto teh (ang.: will work, slov.: bom delal) očipvejččina tvori čase in naklone s pomočjo predpon: npr.: ga- za preteklik, predpreteklik, ge- za prihodnjik, da- za pogojnik.

Negacija je $\mathrm{v}$ očipvejščini tako posebna, razvita in raznolika, da se ne da povzeti

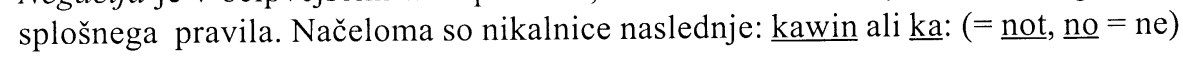
ali $\underline{\text { kego }}(=\underline{\text { do }} \underline{\text { not }}=$ ne $)$.

Očipvejščina pozna štiri oz. pet naklonov:

a) povedni naklon = indikativ;

b) sibžonktiv (subjonctif), ki izraža nekakšno predpostavko: glagoli v tem naklonu imajo poleg posebnih spregatvenih končnic pred seboj sibžonktivni znak, npr.: missawa: Nin minwendam, missawa kitimagisiian (kitimagisian je glagol v sibžonktivnem naklonu) (Sem srečen, čeprav sem reven.);

c) pogojnik, znak zanj je predpona da-, npr.: Wissinissiwan nin da bakade. (= Če ne bom jedel, bom lačen); pogojnik je lahko izražen tudi z znakom gonima ali kema;

č) velelni naklon: znak zanj je $\underline{\mathrm{iw}}$; 
d) Specifični naklon, ki ga Baraga le pogojno šteje med naklone, je dubitativ. O dubitativu Baraga v slovnici zelo natančno in podrobno razpravlja: gre za t. i. »dvomilni naklon«, ki je bil v očipvejščini zelo razširjen, saj so ga Indijanci uporabljali za upovedovanje vsega, kar niso videli na lastne oči. Nekje Baraga celo pristavi, da bi utegnilo to kazati na močno zasidrano nezaupanje v sočloveka, saj Očipvejci ta dubitativ uporabljajo tudi za vse, kar so jim drugi povedali, torej za ubeseditveni sistem «relata refero«. Baraga kot misijonar poudarja, da se morajo duhovniki pri govoru o verskih stvareh dubitativu izogibati, čeprav ga Indijanci hočejo uporabljati tudi na verskem področju. Gre torej za močno psiholingvistično kategorijo.

Očipvejščina ima devet konjugacij: gre za zapleten spregatveni sistem. Bistvena za prepoznavo umestitve v ustrezno konjugacijo je 3. oseba ednine sedanjika povednega naklona. Ker pa je te končnice pogosto težko vedeti oz. se jih je težko naučiti, Baraga opozarja, da jih bo v slovarju pri glagolih sproti navedel. Glagoli se delijo v konjugacije glede na več karakteristik:

- glede na tranzitivnost oz. netranzitivnost,

- glede na kategorijo živosti,

- glede na enoosebne glagole (samo v 3. os. - za naravne pojave, npr. mrzlo je),

- glede na tipične končnice za 3. os. ed. sed. povednega naklona.

Že iz zgoraj povedanega se da sklepati, da ima očipvejščina izjemno zapleten glagolski sistem. Na zapletenost slovnične kategorije glagola v očipvejščini kaže že dejstvo, da je Baraga v slovnici tvorbi glagolskih oblik posvetil kar 200 strani.

Za vsaj osnovno predstavo podajam primer za 1. konjugacijo:

Sedanjik je treba znati: (pov. n., trdilna oblika):

$\begin{array}{lll}\text { 1. } & \text { Nind } \underline{\mathrm{ikit}}(=\mathrm{I} \underline{\mathrm{say}}=\text { rečem }) & \text { 1. nind } \underline{\mathrm{ikitomin}} \\ \text { 2. } & \text { kid } \underline{\mathrm{ikit}} & 2 . \underline{\text { kid }} \underline{\mathrm{ikitom}} \\ \text { 3. } & \text { - ikito } & \text { 3. } \text { - ikitowag }\end{array}$

Perfekt: predpona gi- + cel sedanjik: nin gi-ikit

ki gi-ikit

Imperfekt: 3. os. sedanjika + nabam (v 1.os): nind ikitonabam

Pluskvamperfekt: predpona gi- + imperfekt: nin gi-ikitonaban

Futur: predpona gad- + sedanjik: nin gad-ikit (= I will say $=$ rekel bom)

\section{Poglavje IV: Pridevnik}

V očipvejščini je pridevnik nepregibna besedna vrsta, torej se ne spreminja v spolu, sklonu in številu.

\section{Poglavje V: Števniki}

Poleg glavnih, vrstilnih, množilnih in ločilnih števnikov je posebnost očipvejščine (vsaj glede na slovenščino) kategorija distributivnih števnikov: gre za tip dva po dva.

\section{Poglavje VI: Predlogi}

Npr.: $\underline{\text { nawaii }}(=\underline{\text { in the }} \underline{\text { middle }}=$ sredi); $\underline{\text { megwe }}(=\underline{\text { among }}=$ med $)$. 
- Poglavje VII: Prislovi

Očipvejščina pozna 10 vrst prislovov.

Primer za časovni prislov: sesika ( $\underline{\text { suddenly }}=$ nenadoma $)$.

\section{Poglavje VIII: Vezniki}

Očipvejščina pozna tako priredne veznike, npr.: gaie $(=\underline{\text { and }}=$ in $)$, kot tudi podredne veznike, npr.: kishpin $(=\underline{\text { if }}=\breve{c} e)$.

\section{Poglavje IX: Medmeti}

Hoi! haw! (izgovor z aspiriranim h) (=živjo).

\section{Tretji del: Skladnja (Part III: Syntax)}

\section{Poglavje I: Skladnja samostalnikov}

Pri samostalnikih sta v očipvejščini pomembni dve skladenjski pravili:

Vpliv skladenjskega predmeta, ki je živi samostalnik, na glagol kot povedek glede števila:

Predmet v množini povzroči, da dobi enako »množinsko končnico« tudi glagol, npr. Nin sagiton masinaigan. (Berem knjigo.) Nin sagitonan masinaiganan. (Berem knjige.)

Torej: samostalniška množinska končnica se iz samostalniškega skladenjskega objekta prenese tudi na glagol. (Tega slovenščina ne pozna, tudi angleščina ne, morda nekaj podobnega v francoščini: - v passé composé pri participu pasé, kadar je skladenjski predmet ženskega spola ali v množini in je kot zaimek pred glagolom: Il a construit les maisons. > Il les a construites.)

Vpliv samostalnika kot skladenjskega subjekta na glagol kot povedek glede kategorije živosti:

Živi samostaniki. zahtevajo ob sebi žive glagole (animate noun + animate verb), to je glagole IV. in V. konjugacije: to so oboji tranzitivni gl., končujoči se na -an (IV.) ali -nan (V.) v 3. os. edn.

Neživi samostalniki zahtevajo ob sebi nežive glagole (inanimate noun + inanimate verb), to je glagole VI. konjugacije: tudi ti glagoli so tranzitivni, v 3. os. ed. sed. se končujejo na -an, -en, -in, -on. Vendar, kot pokaže podrobni pregled konjugacij v Baragovi slovnici (okrog 100 strani), je v vseh časih, načinih, naklonih pri vsaki od devetih konjugacij toliko različnih končnic, da je to področje zelo težko obvladljivo, kar poudarja tudi Baraga. - Zato je razumljivo (upam), da sem ob tem pregledu slovnice problem le nakazala.

\section{Poglavje II: Skladnja glagolov}

Pri glagolih sta v očipvejščini pomembni dve skladenjski pravili:

Ujemanje glagola s samostalnikom glede kategorije živosti.

Za zaporedje osebek, povedek v očipvejščini ni pravila: glagol kot povedek je lahko pred ali za subjektom (pomembna razlika glede na angleščino!). 


\section{Poglavje III: Stavčna (besedna) analiza}

Baraga pravi, da je stavčna analiza »anatomija slovnice«. Za vsako besedno vrsto sistematično povzame, kaj ji določimo, nato pa sledi stavčna besedna analiza na dveh konkretnih primerih: eden od teh je: Sagiada Jesus, win sa nitam ki gi-sagiigonan. (= Let us love Jesus, because he has first loved us. = Ljubimo Jezusa, ker/saj nas je on prvi ljubil.)

Tak način predstavlja nekakšen pregleden povzetek vseh slovničnih kategorij, obravnavanih $\mathrm{v}$ slovnici, in daje bralcu možnost preverjanja njegovega razumevanja $\mathrm{v}$ slovnici popisanih jezikovnih struktur očipvejskega jezika.

\section{Zaključni konkretno učbeniški del Baragove slovnice A Theoretical and Prac- tical Grammar of the Otchipwe Language}

Baraga navede nekaj pogovornih fraz in dva konkretna pogovora med misijonarjem in Očipvejcem (seveda $v$ očipvejščini in $z$ dodanim angleškim prevodom). $S$ tem Baraga v slovnici pokaže na živo besedilno rabo očipvejščine.

\section{Za sklep prikaza Baragove slovnice $A$ Theoretical and Practical Grammar of the Otchipwe Language}

Nekaj splošno pomembnih razsežnosti Baragove slovnice:

Jezikoslovno pionirska razsežnost (Baragove) slovnice v smislu jezikoslovne pisne in posledično književne konstitutivnosti očipvejščine in s tem njene uradne registracijske umestitve $v$ skupnost jezikov:

Baraga je opravil prvi jezikovni opis oz. prvo celostno predstavitev očipvejščine: slovnica je oblikovana na temelju govorjenega jezika, zato je bilo potrebno oblikovanje osnovnega pisnojezikovnega »orodja«: osnovanje oz. uvedba črkopisa, primernega glasovom očipvejskega jezika, ter popis navodil za izreko. (V tem smislu bi Baragovo delo za očipvejščino v primeru slovenščine lahko primerjali z delom Primoža Trubarja in drugih naših protestantskih piscev.)

Socio- in psiholingvistična razsežnost (Baragove) slovnice v smislu kulturološke specifičnosti. Gre za slovnični popis jezika Očipvejcev kot enega od plemen Indijancev: $v$ primerjavi z vladajočo strukturo angleško ali francosko govorečih Američanov so Očipvejci (oz. so bili v Baragovem času) primitivni domorodci s svojo duhovno sfero, ki ima seveda vedno odraz v jeziku (npr. kategorija dubitativa, kategorija živosti v povezavi z »živimi samostalniki in živo spregatveno kategorijo«, ki očipvejščino uvršča v t. i. aktivne jezike (nasproti ergativnim). Lahko torej rečemo, da je Baraga s svojo slovnico opravil veliko nalogo tudi v okviru »družbenostnega jezikoslovja $\ll^{5}$.

Večjezikovno primerjalna razsežnost (Baragove) slovnice v smislu prikaza jezikovnostrukturnih specifičnosti očipvejščine, npr.: tipi konjugacij; tvorjenje časov s predponami; v vsakem poglavju primerjava vsaj z angleščino, ki je pač do določene mere nujna, saj je slovnica pisana v angleščini. Vendar Baraga posamezne jezikov-

5 Za Baragovo »družbenostno jezikoslovje« sem že ob predstavitvi njegovega slovarja $A$ Dictionary of the Ojibway Language (Jezikoslovni zapiski 6) zapisala, da bi v njegovem primeru lahko po Prešernovo rekli, »da iz srca svoje je kali pognalo.« 
ne pojave primerja tudi z drugimi jeziki, pogosto s francoščino, včasih tudi z latinščino, z grščino, npr.: na začetku poglavij vedno poda definicijo, na primer kaj razume pod izrazom »ortografija« (ne pravopis, ampak črkopis), kaj pod izrazom »etimologija « (besedne vrste) ipd.

Slovarsko konceptualna razsežnost (Baragove) slovnice $A$ Theoretical and Practical Grammar of the Otchipwe Language v tem smislu, da je Baraga v slovnici popisal jezikovno strukturo očipvejščine, jo obenem konkretiziral s številnimi primeri iz očipvejščine, vse to pa sinhroniziral s slovaropisno perspektivo, saj celo sam v Uvodu v slovnico poudari, da jo piše tudi z mislijo, kako bodo določena jezikovna dejstva očipvejščine lahko prikazana in $z$ angleščino soočena v slovarju, ki je nato tri leta po izidu slovnice, tj. leta 1853, izšl z naslovom $A$ Dictionary of Otchipwe Language (explained in English). 